\author{
Magdalena DOBISZEWSKA ${ }^{1}$ \\ Wojciech FRANUS ${ }^{2}$ \\ Sylwia TURBIAK ${ }^{3}$
}

\title{
ANALIZA MOŻLIWOŚCI ZASTOSOWANIA ODPADOWEGO PYŁU BAZALTOWEGO W ZAPRAWIE CEMENTOWEJ
}

\begin{abstract}
Rosnące zapotrzebowanie na surowce naturalne do produkcji materiałów budowlanych, spowodowało intensyfikację badań dotyczących możliwości wykorzystania w produkcji budowlanej materiałów odpadowych. Powszechnie, jako dodatek mineralny do cementu stosowany jest granulowany żużel wielkopiecowy, popiół lotny, czy też pył krzemionkowy. Podczas obróbki kruszywa stosowanego do produkcji mas mineralno-asfaltowych (MMA) powstają duże ilości odpadów pylastych. Utylizacja tych odpadów stanowi obecnie duży problem w wielu wytwórniach MMA. W pracy dokonano analizy możliwości zastosowania odpadowego pyłu bazaltowego do produkcji zaprawy cementowej. Najpierw zbadano właściwości fizyczne i chemiczne zastosowanego pyłu bazaltowego. Celem określenia wpływu dodatku pyłu bazaltowego na niektóre właściwości zapraw przygotowano cztery mieszanki, w których pył bazaltowy stanowił częściowy zamiennik piasku w ilości 0-30\% masy piasku. Badania doświadczalne dotyczyły analizy wpływu pyłu na wytrzymałość zapraw na ściskanie i zginanie po 2, 28 i 56 dniach dojrzewania próbek, mrozoodporności, nasiąkliwość oraz zdolności do kapilarnego podciągania wody. Następnie przeprowadzono badania dotyczące wpływu dodatku pyłu bazaltowego na mikrostrukturę oraz porowatość zaprawy. Wyniki przeprowadzonych badań wskazują na to, że pył bazaltowy może być stosowany do produkcji zapraw cementowych, jako substytut piasku naturalnego. Zastąpienie części piasku w zaprawie cementowej przez pył bazaltowy pozwoli na zagospodarowanie odpadu przemysłowego oraz wpłynie na poprawę niektórych cech zaprawy cementowej.
\end{abstract}

Słowa kluczowe: pył bazaltowy, wytrzymałość zapraw, mrozoodporność, porowatość zapraw, zagospodarowanie odpadów

\footnotetext{
${ }^{1}$ Autor do korespondencji/corresponding author: Magdalena Dobiszewska, Uniwersytet Technologiczno-Przyrodniczy w Bydgoszczy, Al. prof. S. Kaliskiego 7, 85-796 Bydgoszcz, +48 523408389, magdadob@utp.edu.pl

${ }^{2}$ Wojciech Franus, Politechnika Lubelska, Wydział Budownictwa i Architektury, ul. Nadbystrzycka 40, 20-618 Lublin, +48 815384416, w.franus@pollub.pl

${ }^{3}$ Sylwia Turbiak, Uniwersytet Technologiczno-Przyrodniczy w Bydgoszczy, Al. prof. S. Kaliskiego 7, 85-796 Bydgoszcz, +48 690187048, sylwia.turbiak.utp@wp.pl
} 


\section{Wprowadzenie}

Negatywnym skutkiem uprzemysłowienia gospodarki jest niewątpliwie wzrost produkcji odpadów przemysłowych. Bezpieczna utylizacja tych odpadów stanowi poważny problem, zarówno ze względu na ograniczenia dotyczące miejsc ich składowania, jak i rygorystyczne normy środowiskowe związane z ilością i jakością wytwarzanych odpadów. Rosnące zapotrzebowanie na surowce do produkcji materiałów budowlanych doprowadziły do rozwoju badań dotyczących możliwości wykorzystania niektórych odpadów przemysłowych w przemyśle cementowym, np. żużli wielkopiecowych, popiołów lotnych oraz pyłów krzemionkowych. W literaturze przedstawia się badania dotyczące możliwości wykorzystania również innych odpadów [1-10]. Dodatek pyłu marmurowego [1], mączki bazaltowej [2-6, 8-10], granitowej [7] i wapiennej [3], kruszonej ceramiki [8], czy też odpadów rolnych [1], pozytywnie wpływa na właściwości reologiczne zapraw i mieszanek betonowych, wytrzymałość cementu i betonu a także na ich trwałość.

W pracy przedstawia się badania dotyczące możliwości wykorzystania dodatku pyłu bazaltowego w zaprawach cementowych. Pozytywny wpływ pyłu bazaltowego na niektóre właściwości zapraw cementowych zaobserwowany został już wcześniej przez innych badaczy [2-6, 8]. Zmielony bazalt, stosowany jako częściowy substytut piasku, bądź cementu, zwiększa wytrzymałość zapraw cementowych. Wskazuje się na dwie główne przyczyny przyrostu wytrzymałości zapraw wskutek dodatku pyłu bazaltowego. Pierwsza, to efekt wypełnienia porów w matrycy cementowej przez pył i związane z tym doszczelnienie struktury zaprawy oraz wzrost jej gęstości $[3,6]$. Przedstawione w literaturze wyniki badań wskazują również, że zmielony bazalt ma właściwości pucolanowe, co wpływa przede wszystkim na późniejszą wytrzymałość zapraw $[2,3,6]$. Im drobniejsze uziarnienie pyłu, tym większa jego aktywność pucolanowa i tym samym większy przyrost wytrzymałości [3]. Pył bazaltowy wpływa także na inne właściwości zapraw cementowych. Dodatek pyłu opóźnia czas wiązania zaczynu cementowego [2] oraz poprawia urabialność zapraw [4, 5]. Zaobserwowano również wzrost odporności zapraw z pyłem na ścieranie a także mniejszą zdolność do penetracji jonów chlorkowych [8].

\section{Charakterystyka pyłu bazaltowego}

Zastosowane w badaniach pyły, stanowią odpad z produkcji MMA. Odseparowywane są one z kruszywa w procesie jego suszenia. Kruszywa, z których pozyskano pył będący przedmiotem badań, to kruszywa bazaltowe pochodzące z kopalni „RADAN BAZALT" w Sulikowie. Dlatego odpad ten określany jest w pracy, jako pył bazaltowy (skład tlenkowy - tab. 1). Powierzchnia właściwa pyłów wyznaczona aparatem Blaine`a wynosi $3500 \mathrm{~cm}^{2} / \mathrm{g}$ a gęstość $2,99 \mathrm{~g} / \mathrm{cm}^{3}$. 
Tabela 1. Skład chemiczny pyłu bazaltowego PB i cementu CEM [\%]

Table 1. Chemical composition of powder basalt PB and cement CEM [\%]

\begin{tabular}{|l|c|c|c|c|c|c|c|c|c|c|}
\hline \multirow{2}{*}{ Mat. } & $\mathrm{SiO}_{2}$ & $\mathrm{Al}_{2} \mathrm{O}_{3}$ & $\mathrm{Fe}_{2} \mathrm{O}_{3}$ & $\mathrm{CaO}$ & $\mathrm{MgO}$ & $\mathrm{SO}_{3}$ & $\mathrm{~K}_{2} \mathrm{O}$ & $\mathrm{Na}_{2} \mathrm{O}$ & $\mathrm{Cl}^{-}$ & $\mathrm{LOI}$ \\
\cline { 2 - 11 } & \multicolumn{10}{|c|}{$[\%]$} \\
\hline $\mathrm{PEM}$ & 38,16 & 12,68 & 15,88 & 15,16 & 7,66 & 0,20 & 0,83 & 2,91 & 0,068 & 4,16 \\
\hline
\end{tabular}

Badany pył bazaltowy reprezentuje monomodalny typ uziarnienia. Dominują w nim średnice ziaren $\mathrm{w}$ przedziale od 4 do $90 \mu \mathrm{m}$. Największe ilości cząstek zaobserwowano dla średnicy $\mathrm{d}_{(0,5)}=15,86 \mu \mathrm{m}$. Pozostałe parametry charakterystyczne to $\mathrm{d}_{(0,1)}=2,26 \mathrm{i} \mathrm{d}_{(0,9)}=97,99 \mu \mathrm{m}$. W składzie mineralnym badanego pyłu dominują Ca-plagioklazy (anortyt) rozpoznane po charakterystycznych odległościach międzypłaszczyznowych $\mathrm{d}=4,04 ; 3,33 ; 3,28 ; 3,18 \AA$, którym towarzyszą skaleniowce $\mathrm{z}$ grupy nefeliu i zeolit analcym. Rozpoznane odpowiednio po $\mathrm{d}=4,18 ; 3,18 ; 3,00 ; 2,88 ; 2,57 \AA ̊$ i d $=5,58 ; 4,85 ; 3,42 ; 2,92 \AA$. Skład mineralny uzupełniają niewielkie ilości pirokseny $\mathrm{z}$ szeregu augitu $\mathrm{d}=4,64 ; 3,23 ; 2,99$; $2,51 \AA$ i amfiboli z grupy hornblendy $\mathrm{d}=8,40 ; 4,51 ; 3,09 \AA$.

\section{Istota i program badań}

Rozważany w pracy problem dotyczy analizy możliwości wykorzystania pyłu bazaltowego, jako składnika zaprawy cementowej. Istota badań polegała na tym, że pył ten dodawany był do zaprawy cementowej w taki sposób, że zastępował część piasku. W celu określenia wpływu dodatku pyłu bazaltowego na właściwości zaprawy, zbadano cztery różne zaprawy cementowe. Przeprowadzono badania zaprawy referencyjnej $\mathrm{C} 0$ (bez dodatku pyłu) oraz trzech zapraw doświadczalnych $\mathrm{C} 1, \mathrm{C} 2$ i C3, w których dodatek pyłu stanowił odpowiednio 10, 20 i 30\% masy piasku. Wszystkie badane zaprawy wykonano z cementu portlandzkiego CEM I 42,5 R (skład tlenkowy - tab. 1). Skład poszczególnych badanych zapraw cementowych przedstawiono w tabeli 2 .

Badania obejmowały analizę wpływu pyłu bazaltowego na niektóre właściwości stwardniałej zaprawy cementowej, tj. badano wytrzymałość na ściskanie i zginanie (PN-EN 196-1), mrozoodporność (PN/B-04500), nasiąkliwość

Tabela 2. Skład zapraw cementowych

Table 2. Mortar mixture proportion

\begin{tabular}{|c|c|c|c|c|}
\hline \multirow{2}{*}{$\begin{array}{c}\text { Zaprawa } \\
\text { Cementowa }\end{array}$} & Cement & Piasek & Pyt bazaltowy & Woda \\
\hline & \multicolumn{4}{|c|}{$[g]$} \\
\hline CO & \multirow{4}{*}{450} & 1350 & 0 & \multirow{4}{*}{225} \\
\hline$C 1$ & & 1215 & 135 & \\
\hline$C 2$ & & 1080 & 270 & \\
\hline C3 & & 945 & 405 & \\
\hline
\end{tabular}


(PN/B-04500) oraz zdolność do kapilarnego podciągania wody (PN/B-04500). Wszystkie próbki do badań zostały przygotowane i przechowywane zgodnie z normą PN-EN 196-1. Kolejne badania dotyczyły analizy wpływu dodatku pyłu bazaltowego na mikrostrukturę oraz porowatość zapraw cementowych. Obserwację mikrostruktury przeprowadzono za pomocą mikroskopu skaningowego oraz porozymetrii rtęciowej.

\section{Wyniki badań i dyskusja}

Wytrzymałość zaprawy cementowej na ściskanie i zginanie określono odpowiednio na sześciu i trzech próbkach, po 2, 28 oraz 56 dniach dojrzewania (rys.1). Pył bazaltowy pozytywnie wpływa, zarówno na wczesną i normową wytrzymałość zapraw, jak i na wytrzymałość badaną po 56 dniach dojrzewania próbek. W przypadku wytrzymałości na zginanie, największy przyrost w stosunku do zaprawy referencyjnej, odnotowano dla próbek dojrzewających 28 dni wykonanych z udziałem pyłu bazaltowego w ilości 10\%. Wytrzymałość na zginanie wzrosła wówczas o $34 \%$. W przypadku wytrzymałości wczesnej oraz 56 dniowej, zaobserwowano przyrost o ok. $30 \%$ przy udziale pyłu bazaltowego w ilości odpowiednio 20 i $30 \%$ masy piasku. Znacznej poprawie uległa również wytrzymałość na ściskanie. W porównaniu z zaprawą referencyjną, wczesna wytrzymałość na ściskanie zapraw z dodatkiem pyłu w ilości $20 \%$ wzrosła niemalże o $38 \%$. W przypadku natomiast wytrzymałości 28 oraz 56 dniowej zaobserwowano wzrost wytrzymałości o odpowiednio $40 \%$ i prawie $60 \%$ dla zaprawy wykonanej z 30\% udziałem pyłu. Pył bazaltowy charakteryzuje się znacznie mniejszymi wymiarami ziaren od piasku. W wyniku częściowej zamiany piasku na pył, mogło nastąpić doszczelnienie mikrostruktury matrycy cementowej, co jest główną przyczyną przyrostu wytrzymałości zaprawy z pyłem.

a)

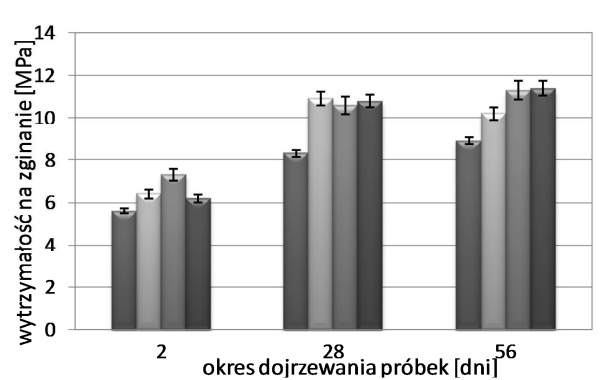

b)

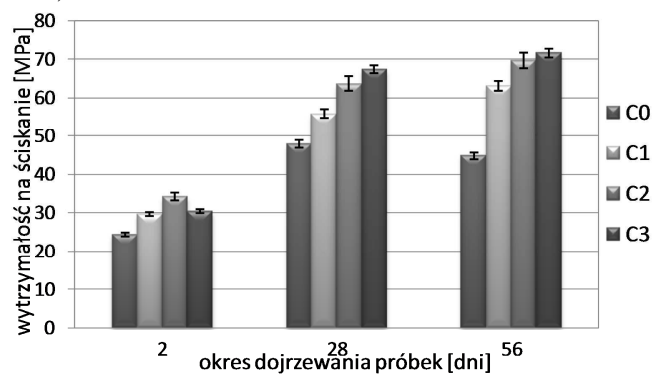

Rys. 1. Wytrzymałość na ściskanie i zginanie zapraw w różnym wieku i o różnej zawartości pyłu

Fig. 1. Compressive and flexural strength of mortar in different curing time and with different powder content 
Doszczelnienie struktury matrycy cementowej przez pył bazaltowy, wpłynęło również na wzrost mrozoodporności zaprawy. Odporność zaprawy na działanie mrozu oznaczono na podstawie zmiany wytrzymałości sześciu próbek poddawanych cyklicznemu zamrażaniu i odmrażaniu w stosunku do sześciu próbek przechowywanych w wodzie, tzw. „świadków”. Próbki referencyjne C0 nie są odporne na działanie mrozu (rys. 2). Po 25 cyklach zamrażania i odmrażania, spadek wytrzymałości na ściskanie w stosunku do próbek „świadków” wyniósł 49\%. Kontynuacja procesu zamrażania i odmrażania doprowadziła do całkowitej destrukcji próbek referencyjnych po 34 cyklach. Dodatek pyłu zwiększył natomiast odporność zapraw na działanie mrozu. Wytrzymałość na ściskanie próbek poddawanych oddziaływaniu mrozu obniżyła się o 2,6\%, 3,6\% oraz $8,5 \%$ dla zapraw z udziałem pyłu w ilości odpowiednio $10 \%, 20 \%$ oraz $30 \%$. Po 50 cyklach natomiast, wytrzymałość próbek z $20 \%$ zawartością pyłu nie uległa praktycznie zmianie a w przypadku zapraw $\mathrm{C} 1$ i C3 obniżyła się o odpowiednio $14 \%$ i $5 \%$.

a)

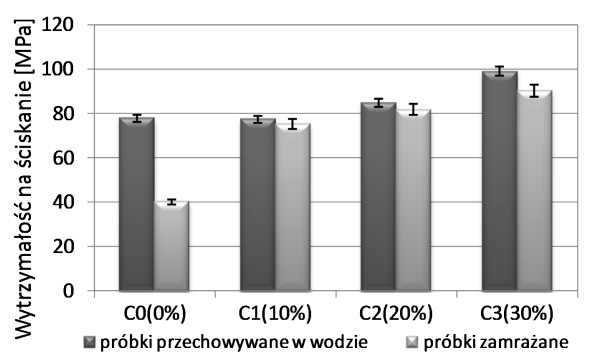

b)

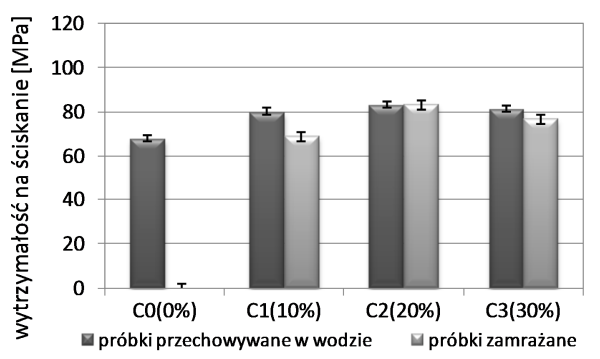

Rys. 2. Wytrzymałość na ściskanie zapraw cyklicznie zamrażanych w funkcji zawartości pyłu bazaltowego: a) 25 cykli zamrażania i odmrażania, b) 50 cykli zamrażania i odmrażania

Fig. 2. Relationship between compressive strength of periodically frozen mortar and basalt powder content: a) 25 freeze-thaw cycles, b) 50 freeze-thaw cycles

W celu oceny wpływu dodatku pyłu bazaltowego na penetrację wody do zapraw cementowych, wykonano badania nasiąkliwości i podciągania kapilarnego wody, zgodnie z PN-85/B-04500. Badania wykonano na trzech beleczkach. Dodatek pyłu bazaltowego w niewielkim stopniu wpływa na nasiąkliwość zapraw. Trudno jest jednak określić wyraźną tendencję. Pył w ilości 10\% masy piasku spowodował obniżenie nasiąkliwości z 7,6\% do 7,1\%. Przy dodatku pyłu natomiast w ilości $20 \%$ i $30 \%$ odnotowano wzrost nasiąkliwości do wartości odpowiednio $8,8 \%$ i 8,5\%. Zdolność do kapilarnego podciągania wody określono na podstawie pomiaru przyrostu masy próbek (rys. 3). Zaprawa z pyłem bazaltowych ma mniejszą zdolność do kapilarnego podciągania wody, niż zaprawa referencyjna. 


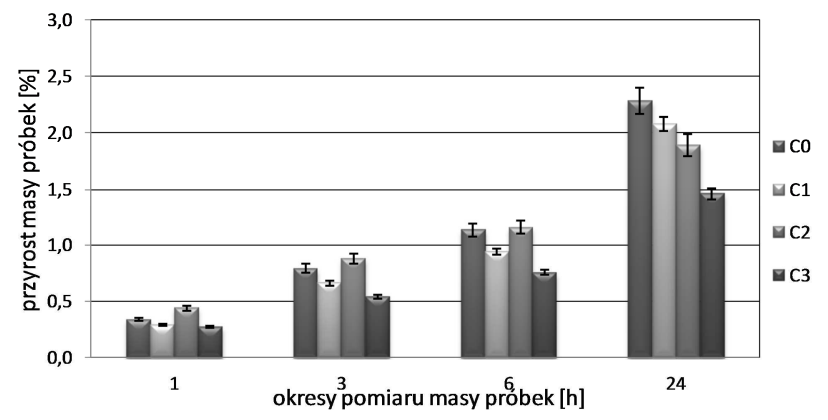

Rys. 3. Przyrost masy zaprawy w wyniku kapilarnego podciągania wody

Fig. 3. Increase of mortar mass as a resulat of capillary rise of water

Mikrostrukturę zapraw z pyłem bazaltowym zbadano przy użyciu elektronowej mikroskopii skaningowej SEM. Wybrane zdjęcia mikrostruktury zaczynów przedstawiono na rys. 4. Dominującymi fazami mineralnymi w badanych zaczynach są C-S-H i portlandyt. Pierwszy z nich występuje głównie w formie siateczkowej - tzw. „plaster miodu”, któremu towarzyszy niewielka ilość form igiełkowych. Natomiast portlandyt będący efektem hydratacji krzemianu trójwapniowego $\left(\mathrm{C}_{3} \mathrm{~S}\right)$ i dwuwapniowego $\left(\mathrm{C}_{2} \mathrm{~S}\right)$, tworzy masywne, heksagonalne kryształy, których agregaty przybierają formy kolumnowe.

Wpływ ilości dodatku pyłu bazaltowego na mikrostrukturę otrzymanych zapraw bardzo dobrze widoczny jest w wynikach pomiarów porozymetrycznych. Wraz ze wzrostem ilości dodatku pyłu bazaltowego, maleje całkowita objętość

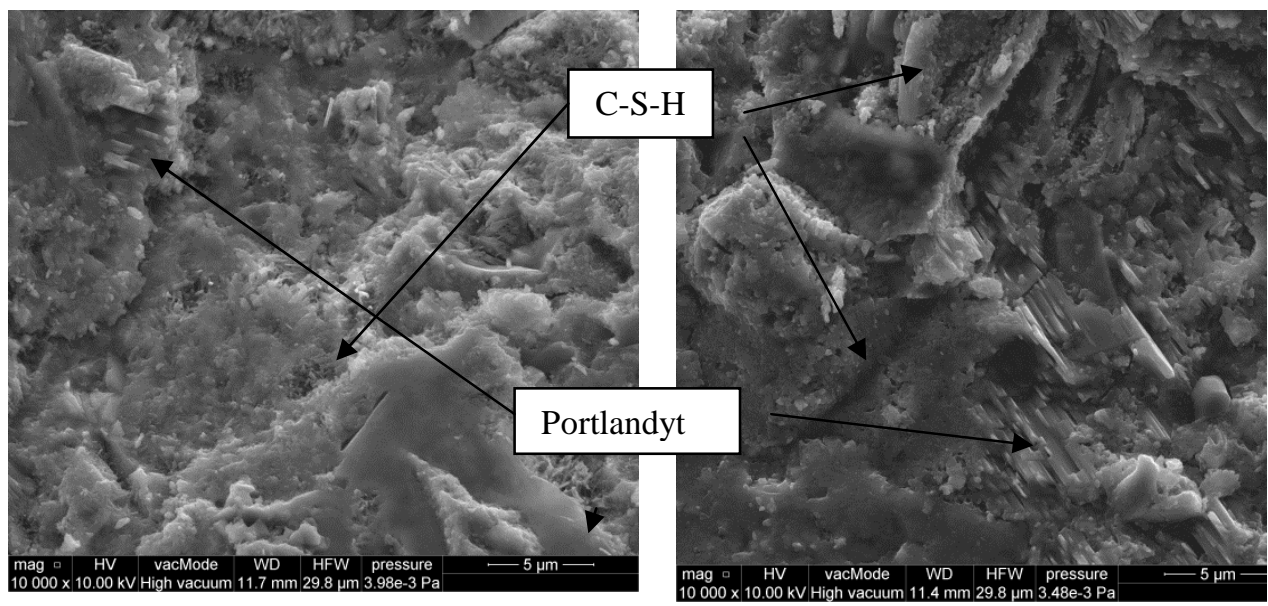

Rys. 4. Mikrostruktura zaprawy bazowej (lewa strona) i z dodatkiem 30\% pyłu bazaltowego (prawa strona) po 28 dniach dojrzewania. SEM, pow. 10000X

Fig. 4. Mortar base microstructure (left side), and with $30 \%$ addition of powder basalt (right side) after 28 days of curing time. SEM, 10000X 
porów $\left(\mathrm{cm}^{3} \cdot \mathrm{g}^{-1}\right)$, średnia średnica porów $(\mu \mathrm{m})$ oraz porowatość $(\%)$. Dla bazowej zaprawy całkowita objętość porów wynosiła $0,1 \mathrm{~cm}^{3} \cdot \mathrm{g}^{-1}$ próbki, natomiast dla zapraw $\mathrm{z}$ dodatkiem $30 \%$ pyłu bazaltowego zmalała do wartości $0,07 \mathrm{~cm}^{3} \cdot \mathrm{g}^{-1}$. Średnia średnica porów wyliczona w oparciu o pole powierzchni bocznej porów i objętości porów zmniejsza się z $0,013 \mu \mathrm{m}$ (dla zaprawy bazowej) do $0,10 \mu \mathrm{m}$ dla zaprawy z dodatkiem $30 \%$ pyłu bazaltowego. Porowatość badanych zapraw wynosiła 20,33 \% dla C0 i 17,68\% dla C3. Wyniki te wskazują, że dodatek pyłu bazaltowego do zaprawy cementowej powoduje doszczelnienie jej struktury, co przekłada się na wzrost wytrzymałości na zginanie i ściskanie.

\section{Podsumowanie}

Przeprowadzone badania potwierdzają, że dodatek odpadowego pyłu bazaltowego pozytywnie wpływa na wytrzymałość i mrozoodporność zapraw cementowych. Pył bazaltowy dodany do zaprawy w zamian za piasek, doszczelnia strukturę matrycy cementowej, czego efektem jest poprawa wytrzymałości i mrozoodporności zapraw. Fakt doszczelnienia struktury zaprawy, potwierdzony został w wyniku badania porowatości. Dodany do zaprawy pył wpłynął na obniżenie porowatości. Zmniejszeniu uległa średnica porów w efekcie czego zmniejszyła się całkowita objętości porów.

Ograniczenie ilości wytwarzanych odpadów przemysłowych jest jedną z podstawowych zasad zrównoważonego rozwoju. Pył bazaltowy, będący przedmiotem badań przedstawionych w pracy jest odpadem powstającym przy produkcji mas mineralno-asfaltowych. Wykorzystanie pyłu w produkcji budowlanej wpłynie pozytywnie na niektóre cechy zapraw i betonów cementowych a także pozwoli na efektywne zagospodarowanie odpadów produkcyjnych.

\section{Literatura}

[1] Neeraj J.: Effect of nonpozzolanic and pozzolanic mineral admixtures on the hydration behavior of ordinary Portland cement, Construction and Building Materials 27 (2012), pp. 39-44.

[2] Liu L., Zhang Y., Zhang W., Liu Z., Zhang L.: Investigating the influence of basalt as mineral admixture on hydration and microstructure formation mechanism of cement, Construction and Building Materials 48 (2013), pp. 434-440.

[3] Soroka I., Setter N.: The effect of fillers on strength of cement mortar, Cement and Concrete Research, Vol. 7 (1977), pp. 449-456.

[4] Uncik S., Kmecova V.: The effect of basalt powder on the properties of cement composites, Concrete and Concrete Structures 2013 Conference, Procedia Engineering 65 (2013), pp. 51-56.

[5] Kmecova V., Stefunkova Z. Effect of basalt powder on workability and initial strength of cement mortar, Journal of Civil Engineering and Architectural Research, Vol. 1, No. 4, 2014, pp. 260-267. 
[6] Saraya M. E. I.: Study physico-chemical properties of blended cements containing fixe amount of silica fume, blast furnace slag, basalt and limestone, a comparative study, Construction and Building Materials 72 (2014), pp. 104-112.

[7] Arivumangai A., Felixkala T.: Strength and durability properties of granite powder concrete, Journal of Civil Engineering Research 2014, 4(2A), pp. 1-6.

[8] Binici H.: Effecct of crushed ceramic and basaltic pumice as fine aggregates on concrete mortars properties, Construction and Building Materials 21 (2007), pp. 11911197.

[9] Dobiszewska M.: Beton z dodatkiem mineralnego pyłu odpadowego, Materiały Budowlane, 5/2015, s. 63-64.

[10] Dobiszewska M., Franus W.: Wpływ dodatku mączki bazaltowej na niektóre właściwości betonu zwykłego, Wybrane zagadnienia konstrukcji i materiałów budowlnych oraz geotechniki, Wydawnictwa Uczelnianie Uniwersytetu Technologiczno-Przyrodniczego w Bydgoszczy, 2015.

\section{ANALYSIS OF THE POSSIBILITY OF USING POWDER BASALT IN CEMENT MORTAR}

\section{S u m m a r y}

Growing demand for natural resources used for building materials production led to intensification research concerning the possibility of using by-products. Granulated blast furnace slag, fly ash and silica fume are used as a supplementary cementitious materials. Asphalt mixture production leads to formation of significant amounts of mineral powder. Utilization of this waste is a problem in Asphalt Batch Mix Plant. The present study analysed the possibility of using basalt powder in cement mortar. The physical properties and chemical composition of powder basalt were firstly studied. Four cementitious mortars were prepared with powder basalt as a partial substitute of sand in amount of 0-30\% sand mass. Experiments were carried out to determine an influence of powder basalt on some properties of cementitious mortar. The compressive and flexural strength at 2, 28 and 56 days of curing, freeze resistance, absorptivity and capillary rise of water were conducted. Secondly, SEM test and mercury porosimetry test were conducted to investigate microstructure of a mortar with powder basalt. The results show that powder basalt can be use as an effective substitute of fine aggregate in cementitious mortar. Use of the powder basalt as a partial substitution of sand anable for the management of industrial waste and improves some properties of cementitious mortar.

Keywords: powder basalt, compressive strength, freeze resistance, porosity, waste management

Przestano do redakcji: 07.06.2016 r.

Przyjęto do druku: 30.06.2016r.

DOI: $10.7862 / r b .2016 .12$ 